\title{
Digital Design and Application Strategy of Intangible Cultural Heritage Presentation
}

\author{
Jiamin Fan \\ China Academy of Art, Shanghai Institute of Design, No.109 Chunxiao Road, Zhangjiang High-tech \\ Park, Pudong New Area, Shanghai, 201203, China.
}

396322633@qq.com

Keywords: Digital Technology; Intangible Cultural Heritage; Development; Succession.

\begin{abstract}
In order to protect the intangible cultural heritage, digital technology was applied. Problems in the protection of intangible cultural heritage were analyzed. The specific measures were put forward. Based on the theory of knowledge visualization, information space, virtual reality and experience economy, the digital protection of intangible cultural heritage was studied. The related concepts of intangible cultural heritage and digital were introduced. The results showed that digital technology could protect, inherit and innovate the intangible cultural heritage. Therefore, digital technology plays an important role in the protection of intangible cultural heritage.
\end{abstract}

\section{Introduction}

Since the 1990s, computer technology has been widely used. The digital technology, which is the main representative of information technology, has been developed rapidly and popularized. It has provided great help for the protection of the intangible cultural heritage [1]. However, the intangible cultural heritage is special. The production process is mostly a continuation of long-term accumulation of experience, and the methods of inheritance and development are mainly words and deeds. Non-heritage items have the characteristics of flexibility, regionality and diversity, which also makes their protection more difficult. The existence of intangible cultural heritage is associated with human activities. It is a dynamic culture. These characteristics have put forward the need for the protection and inheritance of the intangible cultural heritage, which are different from that of the material and cultural heritage [2]. By observing the development process of human civilization, the intangible cultural heritage of all ethnic groups has a similar continuation. Writing is an important technical means for its long-term succession. Now, digital technology has replaced the task of paper. It is the most important means to record and publicize the value of the intangible cultural heritage.

\section{Research Status of Digital Protection of Intangible Cultural Heritage}

The research on the digital protection of cultural heritage began in 1970s at home and abroad. UNESCO has carried out a series of related activities, such as "the memory of the world in Lijiang, China". The United States has been a world leader in digital technology, such as the 1993 National Information Infrastructure Action Plan and the 1994 Digital Library Initiative. While digitizing their own cultural heritage, other ancient civilizations of the world have also been developed and utilized. The digital work of cultural heritage in Europe began in 1986. It is mainly embodied in the digitization of museums and galleries. The French Museum of Fine Arts Union has used digital technology to collect more than 500,000 works of art. In 1991, the National Art Museum of the United States also made thousands of collections of treasures into CDs. In addition, some international conferences on virtual systems and multimedia, virtual technology or graphics have all set the theme of intangible cultural heritage [3].

In China, the research on digital protection of cultural heritage mainly includes digitization of Terracotta Warriors and Horses of Microsoft Research Institute, digital art of Dunhuang Art in Zhejiang University and digitization of cultural heritage of Three Gorges in Nanjing University. At 
the same time, various digital museums also provide effective methods and experiences for China to use computer multimedia and virtual reality technology to protect, inherit and innovate intangible cultural heritage [4].

\section{The Value and Main Technology of Digital Protection of Intangible Cultural Heritage}

The digital protection of cultural heritage is not only the embodiment of a country's comprehensive national strength, but also an important measure for the construction of advanced culture. As early as the tenth five-year plan in 2000, China highlighted the proposal to speed up the informatization of the national economy and society and emphasized the measures to promote the integration of new industries and related cultural industries [5]. Therefore, the information industry and cultural industries are the two main aspects that have emerged from the revolution in digital technology. It gives new relevance to the industry. With the development of information technology, especially the application of digital photography, three-dimensional information, multimedia and network technology, it provides powerful technical support for the digitalization research and development protection of cultural heritage.

With the rise of the Internet, great progress has been made in protection technology, and people have begun to accept this new style. However, digital protection needs to pay attention to the following aspects. The first is digital modeling. The main modeling here is how to quickly and accurately obtain the three-dimensional information of cultural relics. By using 3D scanner, 3D camera, 3D modeling and image processing technology, the structure information and textures of artifacts can be obtained and saved with high accuracy. It will provide digital materials for the restoration of cultural relics, sharing and other materials. The second is remote sensing and virtual reality. Remote sensing is a new type of technology in archeology at home and abroad. Remote sensing technology is used to detect electromagnetic waves of different substances in order to improve the depth, breadth and accuracy of the exploration of cultural relics [6]. The application of virtual reality technology in the protection of cultural heritage is the formation of realistic 3D effect by computer technology, in order to reproduce ancient cities, archaeological sites and excavation sites.

The digital aided design system contains two aspects. The first is the digital aided design system for the plane pattern. The second is to assist the design of three-dimensional solid arts and crafts. Through the aid design, the original classical patterns and handicrafts are innovated, such as the research of Dunhuang art digital knowledge extraction and assistant creation system of Zhejiang University. In addition, the restoration of intangible cultural relics is also an important part of digital protection. In the past, the restoration of intangible cultural heritage was carried out by hand. The restoration of Terracotta Army requires a large number of staff to work for a long time. Computer technology assisted recovery can achieve a realistic effect. It is of great significance to the digital protection of cultural heritage. In addition, for the protection of intangible cultural heritage like dance, choreography and voice driven techniques are used, such as the reconstruction and exhibition of chime bell music and choreography for safeguarding of ancient Chu-culture [7].

\section{Case Analysis on Digital Protection of Intangible Cultural Heritage}

\subsection{Digital Protection Means of Folk Intangible Cultural Heritage.}

Digital protection exploits and protects folklore by means of digital acquisition and processing, digital restoration and reproduction, digital storage and management, and digital display and dissemination. The use of four digital protection methods follows a certain order. The process of implementing the digital protection mode is shown in Figure 1. 


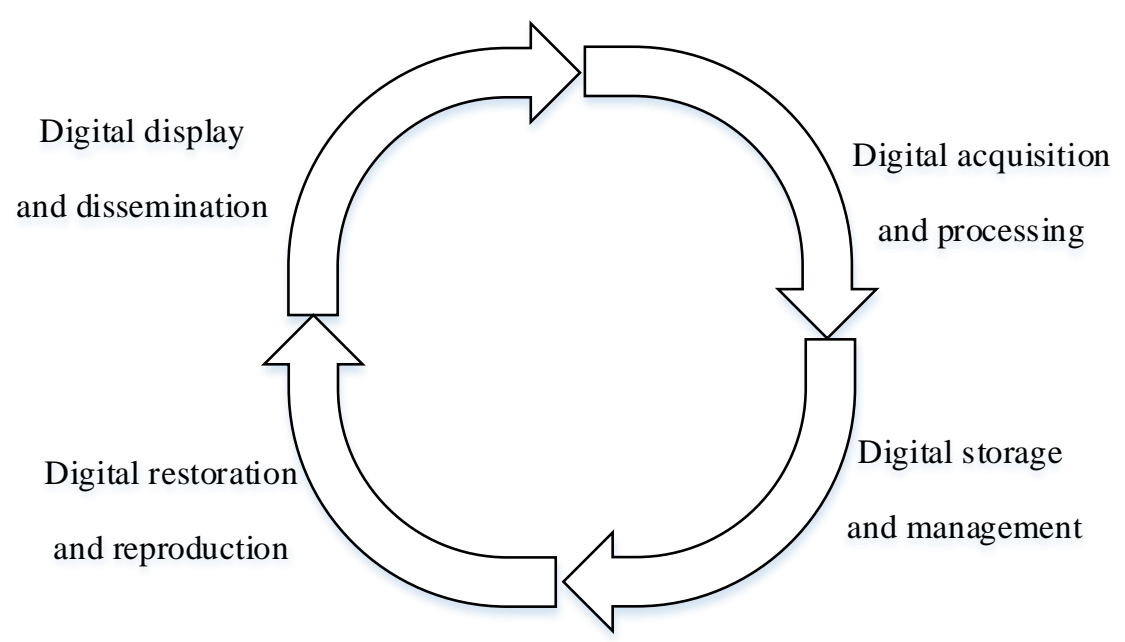

Figure 1. The process of implementing the digital protection mode

Digital acquisition and processing: Collection is the basis for the protection of intangible cultural heritage. Techniques such as graphic scanning, three-dimensional scanning and holographic photography have been used. The folkloric manifestation and cultural space are the objects of collection, and they are kept on the media such as tape, CD and computer. Digital processing is to deal with the non-material cultural heritage of the folklore of the digital form. Through cataloguing, format conversion, compression and graphic processing, the digital information value of the intangible cultural heritage is further promoted.

Digital restoration and reproduction: The protection of intangible cultural heritage focuses on its motility, tradition and integrity. Integrity refers to ensuring the overall ecological and cultural environment of the intangible cultural heritage, which also shows the difficulty of restoration and reproduction of the intangible cultural heritage. Digital repair and reproduction is the reproduction and interpretation of the original environment of intangible cultural heritage by computer graphics, virtual reality and image processing technology, including its scene, ritual process, event process and so on.

Digital storage and management: Relying on CD-ROM, U disk, computer and other carriers, the digital resource base and other platforms are used as the main storage units to preserve the digital form of the intangible cultural heritage. Digital storage and digital management are closely integrated. On the basis of digital storage, digital management integrates the existing digital resources and constructs the digital museum, which is convenient for the network to browse, query, communicate and share.

Digital display and dissemination: The form of digital display includes electronic books, blogs, video, electronic publications and so on. Mobile terminals, such as personal computers and mobile phones, are displayed as the main carriers. Digital communication includes the dissemination and sharing of information. Multimedia technology can easily carry out the operation of capturing, copying and printing data information. Through the Internet platform, information sharing and communication can be carried out anytime and anywhere.

\subsection{Establishment of the Database of Intangible Cultural Heritage}

A database is stored in a computer, and it is a set of institutionalized data. The users of the resource database of the folk intangible cultural heritage are divided into three categories: the user, the maintenance manager and the decision-maker. Users are also divided into general users and researchers. General users use web pages to browse information to meet the needs of interest and knowledge accumulation. Researchers need to acquire more in-depth information by retrieval. The maintenance manager is an internal worker who participates in the data entry of the database, the design of the main body of the page, the maintenance of the function and the management of the operation. While ensuring the normal operation of the database, the data of the database has been continuously expanded. The decision-makers preserve the intellectual property rights involved in the database and take on the responsibility of using the database to promote knowledge and the welfare of 
the society. Under the premise of demand analysis, the database development process of folk intangible cultural heritage database is database retrieval system design, retrieval system production, database development and retrieval system and database test. The design and development of the retrieval system in the network environment determines the degree of openness of the database. Digital protection measures of folklore intangible cultural heritage are shown in Figure 2.

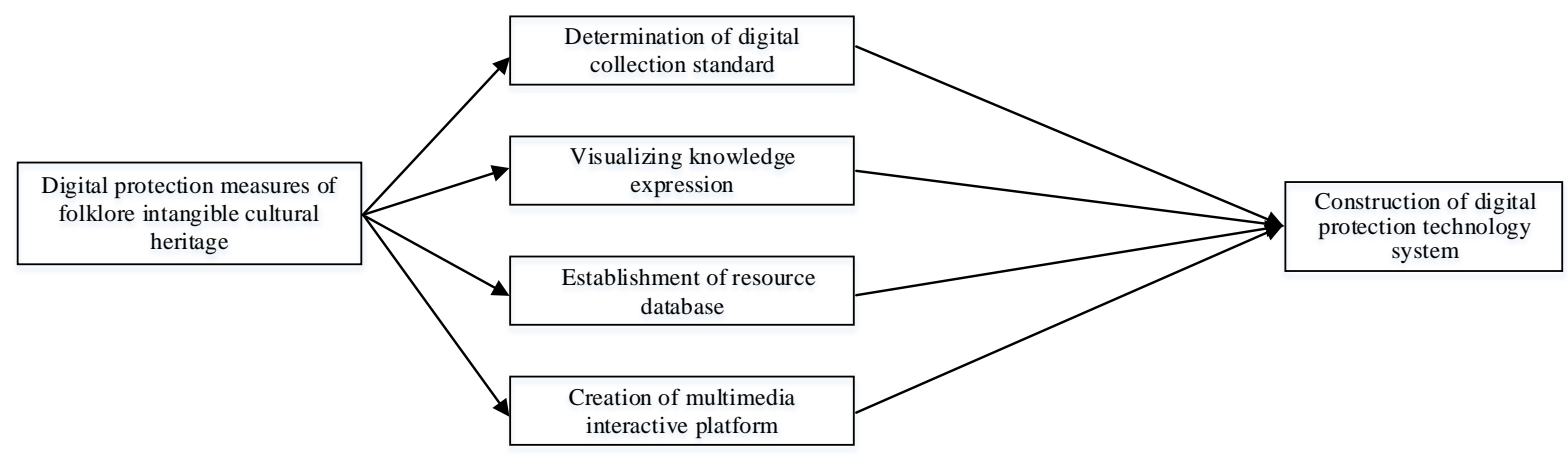

Figure 2. Digital protection measures of folklore intangible cultural heritage

\subsection{Construction of Digital Protection Technology System}

The establishment of digital protection technology system of folk intangible cultural heritage is the exploration and application of digital technology. Based on computers and binary numbers " 0 " and "1", digital technologies mainly act on the collection and storage of graphic audiovisual images of the traditional cultural expressions of the intangible cultural heritage. It is a shallow technology in digital protection. The multimedia presentation of intangible cultural heritage and the virtual reproduction of cultural space require the participation of technologies such as digital technologies, database management and services, scenario modeling and visualization. In order to ensure the integrity of the system, the digital protection technology system for folk intangible cultural heritage should include the relevant technologies involved in digital preservation and protection, digital restoration and reproduction, digital storage and management, and digital display and transmission. Situational modeling is a technique that focuses on the interpretation of the cultural space of folklore intangible cultural heritage. Using this technology to construct three-dimensional scenes and characters, three-dimensional knowledge representation and human-computer interaction are realized. Database management and service technology refer to the unified standard storage, description, management, distribution and retrieval of resources for the realization of folk intangible cultural heritage resources using mass storage and semantic retrieval technologies. Digital protection technologies of folk intangible cultural heritage are shown in Figure 3. The digital protection technology system of folk intangible cultural heritage is shown in Figure 4.

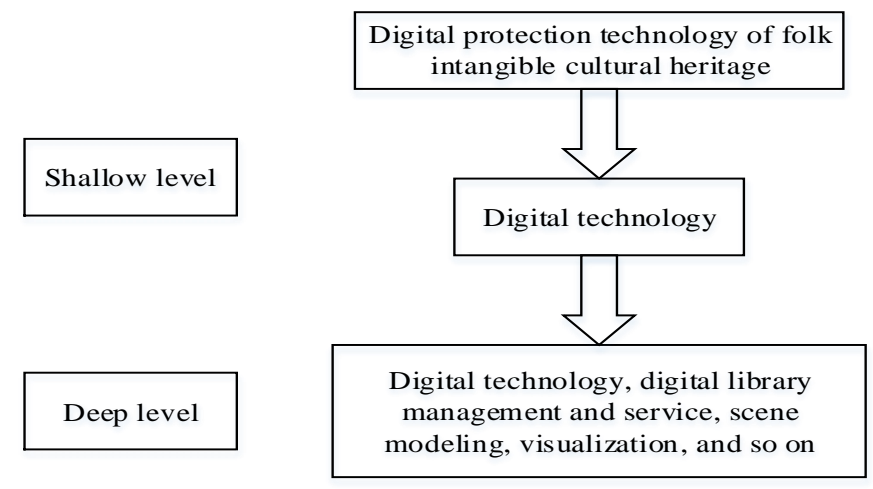

Figure 3. Digital protection technologies of folk intangible cultural heritage 


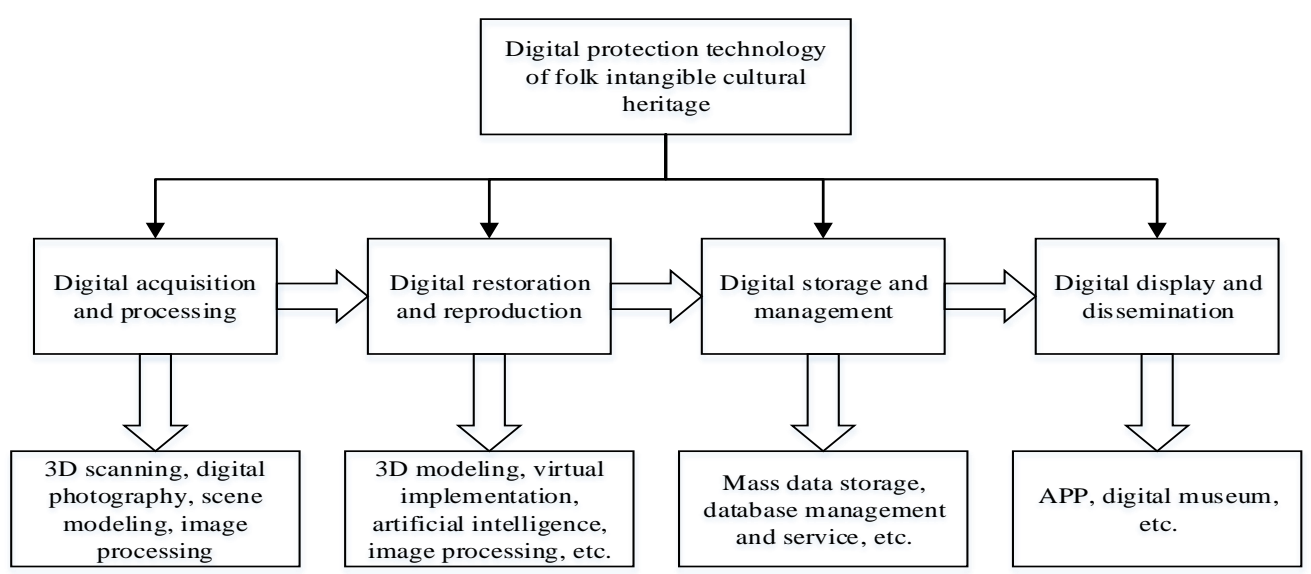

Figure 4. The digital protection technology system of folk intangible cultural heritage

\section{Conclusion}

As an important part of Chinese culture, the development and protection of intangible cultural heritage is of great national and cultural value. Based on the review of domestic and foreign researches, taking the folk intangible cultural heritage as an object, the digital protection mode was introduced. The countermeasures for digital protection of intangible cultural heritage are put forward, that is, the establishment of digital classification and collection standards, the visual expression of knowledge, the establishment of database, the establishment of multimedia interactive platform and the digital protection technology system of intangible cultural heritage. The digital protection project of intangible cultural heritage integrates many theories, methods and techniques of culture and science and technology. In the process of practice, many new problems continue to emerge. This system needs to be perfected in practice.

\section{References}

[1]. Severo, M., \& Venturini, T. (2016). Intangible cultural heritage webs: Comparing national networks with digital methods. New Media \& Society, 18(8), 1616-1635.

[2]. Wang, D., Ma, Q., Wang, X., \& Qi, T. (2017). Another Beautiful Sounds: Building the Memory of Sound of Peddling in Beijing with Digital Technology. World Academy of Science, Engineering and Technology, International Journal of Humanities and Social Sciences, 4(3).

[3]. Idris, M. Z., Mustaffa, N. B., \& Yusoff, S. O. S. (2016). Preservation of Intangible Cultural Heritage Using Advance Digital Technology: Issues and Challenges. Harmonia: Journal of Arts Research and Education, 16(1), 1-13.

[4]. Wilson, K., \& Desha, C. (2016). Engaging in design activism and communicating cultural significance through contemporary heritage storytelling: A case study in Brisbane, Australia. Journal of Cultural Heritage Management and Sustainable Development, 6(3), 271-286.

[5]. Cao, Y. (2017). A Model of Protection of Intangible Cultural Heritage by Commercial Three-Dimensional Animation-Taking "Little Master of Brocade" as an Example. Asian Culture and History, 10(1), 1.

[6]. King, L., Stark, J. F., \& Cooke, P. (2016). Experiencing the digital world: the cultural value of digital engagement with heritage. Heritage \& Society, 9(1), 76-101.

[7]. Dagnino, F. M., Ott, M., \& Pozzi, F. (2015). Addressing Key Challenges in Intangible Cultural Heritage Education. International Journal of Heritage in the Digital Era, 4(2), 193-207. 